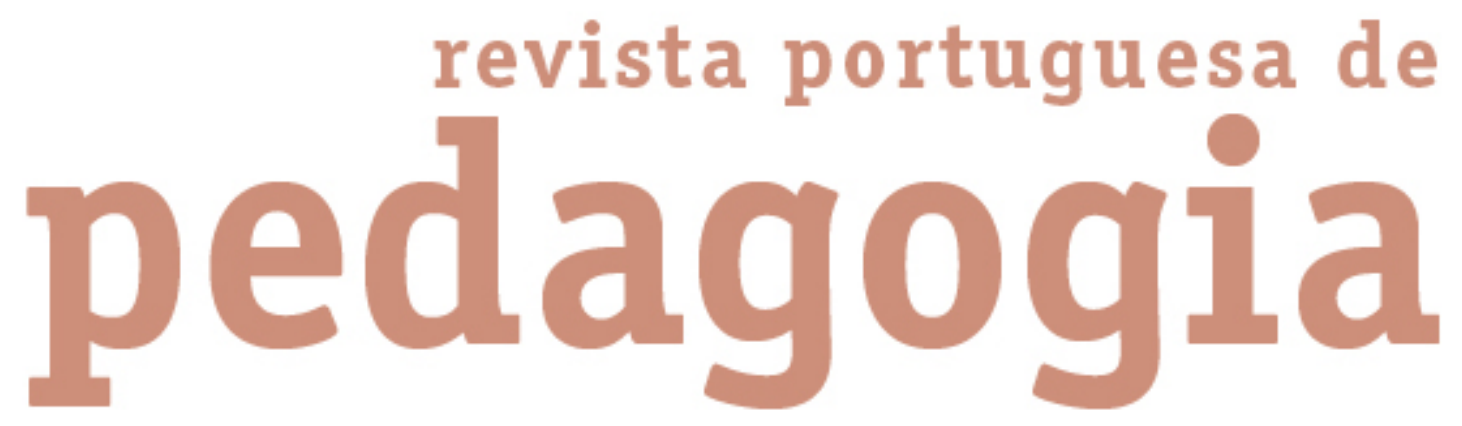

Contribuições de Thomas Gordon para a sustentação de comunidades escolares em ambiente digital

\author{
Autor(es): $\quad$ Paiva, Jacinta; Morais, Carla; Paiva, João \\ URL \\ persistente: \\ URI:http://hdl.handle.net/10316.2/29889 \\ DOI: \\ DOI:http://dx.doi.org/10.14195/1647-8614_42-3_10
}

Accessed : $\quad$ 26-Apr-2023 13:33:13

A navegação consulta e descarregamento dos títulos inseridos nas Bibliotecas Digitais UC Digitalis, UC Pombalina e UC Impactum, pressupõem a aceitação plena e sem reservas dos Termos e Condições de Uso destas Bibliotecas Digitais, disponíveis em https://digitalis.uc.pt/pt-pt/termos.

Conforme exposto nos referidos Termos e Condições de Uso, o descarregamento de títulos de acesso restrito requer uma licença válida de autorização devendo o utilizador aceder ao(s) documento(s) a partir de um endereço de IP da instituição detentora da supramencionada licença.

Ao utilizador é apenas permitido o descarregamento para uso pessoal, pelo que o emprego do(s) título(s) descarregado(s) para outro fim, designadamente comercial, carece de autorização do respetivo autor ou editor da obra.

Na medida em que todas as obras da UC Digitalis se encontram protegidas pelo Código do Direito de Autor e Direitos Conexos e demais legislação aplicável, toda a cópia, parcial ou total, deste documento, nos casos em que é legalmente admitida, deverá conter ou fazer-se acompanhar por este aviso. 

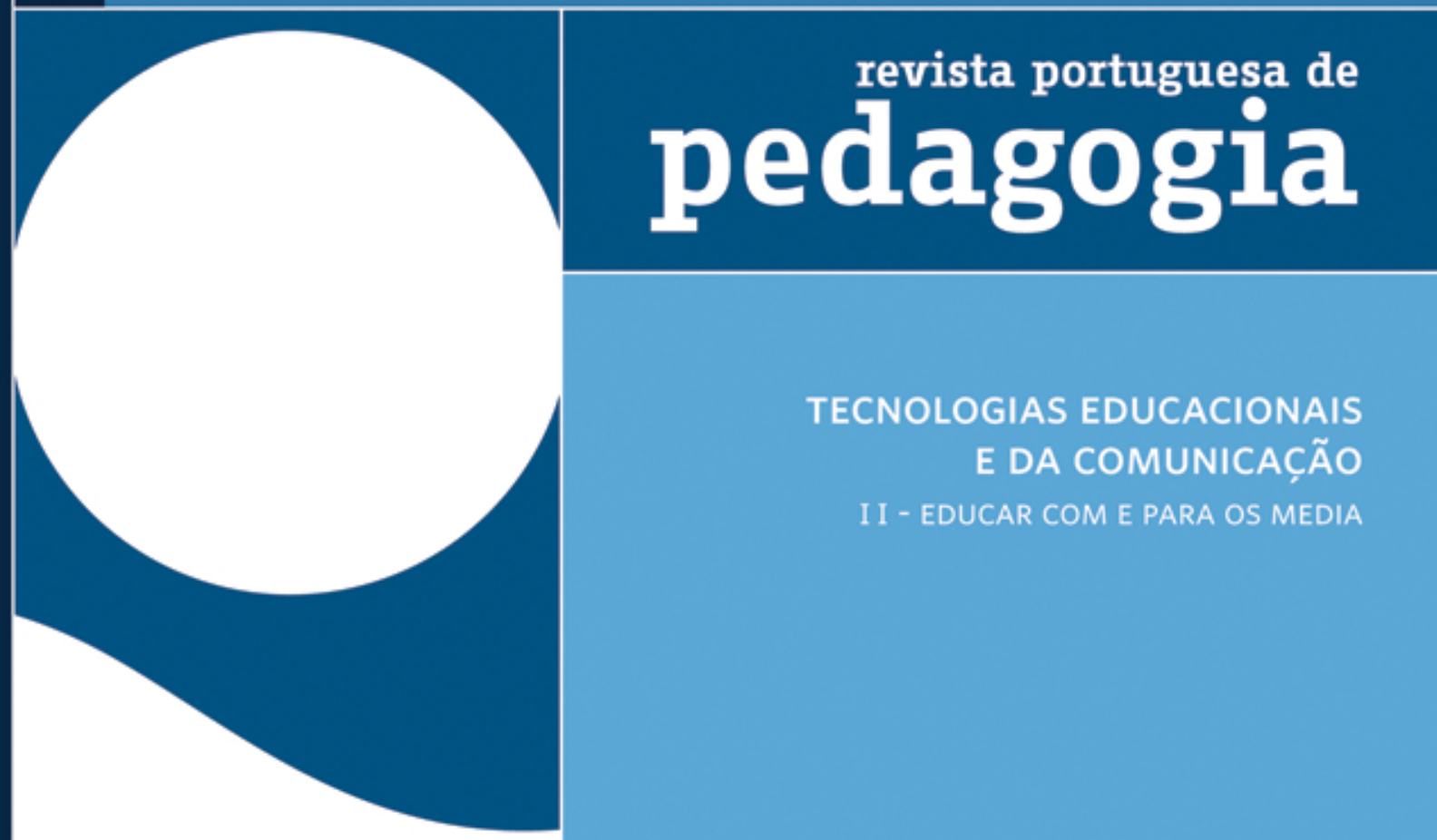

\section{TECNOLOGIAS EDUCACIONAIS E DA COMUNICAC̣ÃO} I I - EDUCAR COM E PARA OS MEDIA 


\title{
Contribuições de Thomas Gordon para a sustentação de comunidades escolares em ambiente digital
}

\begin{abstract}
Jacinta Paiva', Carla Morais ${ }^{2} \&$ João Paiva ${ }^{3}$
Uma das vertentes de mudança na educação passa pela transformação desta num processo de comunicação autêntico, aberto e franco. Não só entre professores e alunos mas também incluindo todos os restantes intervenientes no processo educativo e os encarregados de educação, muito em particular. Só se aprende profundamente dentro de um contexto comunicacional participativo, interactivo e vivencial. As TIC podem, neste contexto, ser uma preciosa alavanca. Na comunicação virtual, estabelecem-se comunidades de aprendizagem, sustentáveis por alguns pilares provenientes das ideias de Thomas Gordon. Este autor coloca de forma muito simples e operacional preceitos da inteligência emocional e de psicologia humanista ao serviço da educação. As suas sugestões foram depois estendidas à escola, tendo fornecido pistas interessantíssimas para a "negociação" afectiva entre alunos, professores e encarregados de educação. Tal contexto pode favorecer a qualidade e quantidade de comunidades digitais em ambiente educativo.
\end{abstract}

\section{Introdução}

Estamos na sociedade de informação! Esta é uma afirmação ouvida vezes sem conta, em contextos variados, associada, ou não, a situações de infoanalfabetização que se pretendem revertidas. Esta ideia serve para dar corpo e justificação às melhores reformas administrativas, passando, por exemplo, por apetrechamentos informáticos de escolas, muitas vezes para, tão só, ser mais um chavão que "fica bem" em qualquer discurso. Em qualquer das situações, seria importante debruçarmo-nos sobre que sociedade de informação é esta. Há que estudar esta nova

\footnotetext{
1 Centro de Física Computacional da Universidade de Coimbra, tIm.: 966304 498, e-mail: jacinta@ netcabo.pt

2 Faculdade de Ciências da Universidade do Porto e Centro de Física Computacional da Universidade de Coimbra, tIm.: 938331777 , e-mail:carlamorais@imediato.pt

3 Faculdade de Ciências da Universidade do Porto e Centro de Física Computacional da Universidade de Coimbra, tIm.: 962505 679, e-mail: jcpaiva@fc.up.pt
} 
forma de organização social, como lhe chama Castells (2000). É muito importante perceber o que é e quem pode pertencer à "rede". Seja nos computadores em si ou nas redes, o futuro (ou o presente?) será eminentemente digital. O Homo digitalis de que nos fala Terceiro (1997) já marca e marcará mais ainda o quotidiano social de todo o mundo. Não há área de actividade e da vida que se não inculque da sociedade digital. Esta sociedade veio para ficar e urge ir vendo, medindo e intervindo para perceber como se estabelece esta nova forma de organização social e como nos organiza ou desorganiza...

Na sociedade tradicional (chamemos-Ihe "sociedade civil") sempre se estabeleceram ricos e pobres (materialmente falando). Passando pelas mais diferentes cambiantes de riqueza, também aqui, nesta sociedade digital, há os que estão dentro (on-line) e os que estão fora (off-line), passando também pelos mais variados graus de utilização da tecnologia digital, desde o "quase nunca" à obsessão compulsiva de não saber viver sem um teclado na ponta dos dedos e "sempre ligado". Em teoria, as Tecnologias de Informação e Comunicação (TIC), e em particular a Internet, poderiam colocar o mundo todo em comunhão... e belíssimas experiências há de solidariedade à escala mundial que avançaram, à "velocidade da luz", graças à rede das redes. A disponibilização da informação multimédia é, em si própria, um potencial benefício. Segundo Dias: "os media do conhecimento favorecem a participação do indivíduo na partilha de assunções, crenças, percepções e representações complexas, e descrevem através deste percurso o próprio objecto da comunicação, o conhecimento que as pessoas comunicam entre si, através dos media e com os media." (2000, p. 143)

Por vezes, o que é digital pode até dispersar ou desorientar os alunos e outros agentes educativos. Numa perspectiva mais optimista, porém, a multiplicidade de informação na Internet permite que, quem a manipula, evolua "através do exercício da sua arte de navegação entre os objectos ou universos de textos, imagens e sons, modela o seu conhecimento privado" (Dias, 1994, pp. 33-34). Além das competências mais pessoais, e não menos importante, as comunidades que se estabelecem por intermédio de plataformas digitais estabelecem relações com uma sociabilidade própria e um contexto muito específico. Tais comunidades virtuais propiciam e potenciam, muito em particular, o trabalho colaborativo (Dias, 2004). Provavelmente constataremos que esta sociedade, "aparentemente" muito mais aberta, livre e disponível que a outra "não digital", se não estivermos atentos, poderá tornar-se uma flor ou uma arma refinadíssima de repetição da sociedade tradicional... só aparentemente aberta, livre e só disponível para alguns. Temos, pois, de ser críticos em relação às 
TIC, à Internet, à sociedade digital. É preciso ensinarmos os mais novos a serem críticos também, mas tendo sempre como pano de fundo o horizonte de possibilidades "milagrosas" que a Internet, em particular, nos traz.

Estarmos à distância de um clique, de alguém, de uma ilha paradisíaca, de uma previsão de tempo para a capital do Burkina Faso, como para o próprio nome da capital do Burkina Faso que não nos ocorre, de uma consulta médica, da supervisão de uma cirurgia ... E este mundo é fabuloso... mas como o mundo dos corais e das ilhas paradisíacas precisa de ser preservado... Há então que viver também nesta sociedade sem ingenuidades pueris, do "tudo é bom", mas com a consciência de pertença e de participantes na construção desta sociedade digital, no sentido de a marcar com o cunho de "estar ao serviço do Homem"....

Ainda estamos profundamente inseridos em organizações autoritárias, em processos de ensino/aprendizagem controladores, com educadores pouco livres, muitas vezes "mal resolvidos", que repetem mais do que pesquisam, que impõem mais do que se comunicam, que não acreditam no seu próprio potencial nem no dos seus alunos. Uma das vertentes de mudança na educação passa pela transformação desta num processo de comunicação autêntico, aberto entre todos os intervenientes no processo educativo. Neste contexto, as TIC podem desempenhar um papel importante.

Na comunicação virtual, estabelecem-se comunidades de aprendizagem, onde as múltiplas identidades que sempre temos e/ou assumimos se podem apresentar facilmente. Como diz Rheingold: "Communicating on-line has different effects on people's identity than other forms of communication. If you think about it, we all use different identities in our daily life. You have a different identity with your mother and father than you do with your husband and wife. And you have a different identity with a stranger you meet on the street or someone in an elevator than you do with someone you work with. We're all used to presenting different faces, different masks to different people. On-line you can create identities that are very different" (1997, inum.).

Usamos muitas vezes a expressão "educar para". Contudo, o grande desafio que se coloca é: "educar em" - em autonomia, em liberdade, em responsabilidade. Educação, autonomia, liberdade, responsabilidade dão-se num elemento fundamental de relacionalidade e de diferença. A aprendizagem adquirida nas escolas representa, hoje em dia, uma parcela cada vez menor da aprendizagem que se adquire no dia-a-dia. A escola já não é mais o espaço privilegiado de aprendizagem. As Tecnologias 
da Informação e Comunicação (TIC) prefiguram um cenário explosivo de oportunidades de auto-educação e de educação à distância, não só na idade escolar, mas também ao longo de toda a vida (Pereira, 2006). Neste contexto, cada vez mais jovens e adultos exigem variedade de canais de aprendizagem, num sistema de elevada escolha. Exigem também maior actividade e interactividade, mobilidade, convertibilidade, conectividade, ubiquidade e globalização.

São várias e distintas as características apontadas por diferentes autores às TIC (Almenara, 1996): interactividade, instantaneidade, inovação, elevados parâmetros de qualidade de imagem e som, digitalização, mais influência sobre os processos do que sobre os produtos, automatização, interconexão, diversidade, etc. As TIC não são por si só a solução milagrosa para nenhum problema educativo, contudo, dadas as suas características, são muitas as vantagens que decorrem da sua utilização em contexto educativo.

Neste artigo referem-se algumas das linhas de pensamento de Thomas Gordon e os caminhos apontados por este autor nas relações entre os pais, os filhos e a escola. Estas ideias são explanadas na perspectiva do desenvolvimento de comunidades virtuais de aprendizagem que podem ser enriquecidas pelas ideias Gordon.

\section{Thomas Gordon e a eficácia educativa}

\subsection{As ideias de Gordon sobre a escola}

As pessoas são diferentes, sentem de maneira diferente e têm opiniões diferentes. Não há necessidade de abdicar disto em nome da união dos professores.

O facto de ter que se ser consistente tem levado muitos professores a sentirem que têm que concordar em todas as situações com os outros professores, "estabelecendo uma (falsa) frente unida" para se apoiarem e para que os alunos vejam que os professores constituem um "bloco" (de gelo?...) e partilham as mesmas opiniões em qualquer situação. Existem sérios perigos desta falsa aceitação.

Os alunos são extremamente sensíveis e observadores no que respeita às tomadas de decisão dos professores e conseguem aperceber-se através de pequenos gestos e/ou emoções dos professores que estão a impor determinada coisa sem concordarem com ela.

Outra forma de falsa aceitação é o mito de que se aceita o aluno, mas não o seu comportamento. A grande falácia deste conceito reside na capacidade de qualquer 
pessoa aceitar genuinamente o aluno, mas ao mesmo tempo, não ser capaz de aceitar o que quer que o aluno faça ou diga.

Também os alunos têm dificuldade em separar-se a eles próprios do seu comportamento. O rectângulo "janela", referido no início, pode ajudar o professor a compreender os seus próprios sentimentos e as condições que influenciam estes sentimentos a mudar constantemente (Gordon \& Burch, 2002).

Quando as pessoas forem, de facto, capazes de sentir e comunicar genuinamente que aceitam os outros, então sim, elas possuem a capacidade de, efectivamente, serem agentes de ajuda. A aceitação dos outros envolve uma relação na qual, a outra pessoa, pode crescer, desenvolver-se, fazer mudanças construtivas, aprender a resolver problemas, ir numa direcção psicologicamente saudável e tornar-se mais produtivo e criativo.

A aceitação é como um terreno fértil que permite que uma pequena semente se desenvolva e venha a ser uma flor. Tal como a semente, a criança (o aluno) também contém a capacidade de se desenvolver e a aceitação é como o terreno - simplesmente permite que a criança ou jovem actualize todo o seu potencial (Gordon, 2005).

\subsubsection{0 ensino que resulta e o ensino que falha}

Ver um jovem a receber algo novo que expanda a sua compreensão acerca do mundo e aumente o seu leque de conhecimentos, é uma observação entusiasmante. Mas, ensinar jovens pode também ser terrivelmente frustrante.

Com demasiada frequência, pais, professores e outros profissionais que trabalham com jovens, constatam que o seu desejo entusiasta de ensinar aos jovens algo de condigno, não é partilhado pelos que aprendem. Pelo contrário, encontram uma teimosa resistência, uma baixa motivação, pequenos intervalos de atenção, um desinteresse inexplicável e uma frequente hostilidade aberta. Isto pode levar a sentimentos de desalento, exasperação e frustração.

São muitos e diferentes os factores que influenciam o resultado dos esforços em ensinar os outros. Gordon (1998) no seu livro Teacher Effectiveness Training ou T.E.T. (traduzido para português como: P.E.E. - "Programa do Ensino Eficaz") - defende a tese de haver um factor fundamental: é o grau de eficácia do professor em estabelecer um tipo particular de relação com os alunos. 
Gordon considera que a qualidade da relação professor-aluno é crucial. Muito mais importante do que aquilo que o professor está a ensinar, é a forma como o faz ou a pessoa que se está a tentar ensinar (Gordon, 1998). Quanto maior for a relação com os alunos, melhor será o ensino que se faz.

\subsubsection{Comunicação: a ligação entre professor e aluno}

É essencial que se saiba que ensinar não é a mesma coisa que aprender. São dois processos diferentes e distintos. É necessário que os professores tenham capacidades de comunicação, de modo a que a sua actividade seja, de facto, eficaz. Estas capacidades não são muito complexas, mas requerem alguma prática. De igual modo, não exigem nada de especial do professor que tenha a ver com mais conhecimento acerca da filosofia da educação ou metodologias e princípios do desenvolvimento da criança. Envolve unicamente falar/conversar. Esta técnica tanto pode afastar como reforçar as relações humanas. Claro que isto representa um determinado "tipo" de conversa e implica o uso de determinadas palavras. O moralismo, tipicamente, quebra o genuíno diálogo. Também é importante uma sensibilidade e um comprometimento extra, nomeadamente a capacidade de adoptar a comunicação de duas vias, isto é, tanto do professor para o aluno como, do aluno para o professor.

\subsubsection{Capacidades testadas, não abstracções vagas}

O programa T.E.T. baseia-se fundamentalmente na ideia, atrás referida, de que a qualidade da relação professor-aluno é crucial se os professores pretendem ser eficazes em ensinar seja o que for. Falamos de qualquer tipo de matéria, qualquer técnica, quaisquer valores ou crenças - tudo pode tornar-se interessante e motivador para os jovens, se o professor criar uma relação com os alunos, em que as necessidades de uns são respeitadas pelos outros.

O programa T.E.T é eminentemente concreto. Foca as principais coisas que os professores podem fazer e dizer, na sala de aula, no dia-a-dia, e deixa de lado os conceitos educacionais abstractos.

\subsubsection{Capacidades que ajudam os alunos a crescer}

O "crescimento e desenvolvimento" dos alunos são normalmente os objectivos de todas as escolas e de todos os professores. No entanto, os métodos utilizados por uns e outros (professores e alunos), muitas vezes, só fazem com que os 
alunos permaneçam dependentes, imaturos e infantis, em vez de potenciarem o desenvolvimento da responsabilidade e encorajarem a independência. Isto não significa, porém, que os professores queiram alunos que sejam irresponsáveis e dependentes. Significa que não Ihes foram ensinadas as técnicas e métodos pelos quais uma pessoa, na sua relação com os outros, pode incentivar a auto-responsabilidade, a autodeterminação, o auto-controlo e a auto-avaliação. Essas qualidades não se desenvolvem acidentalmente, antes devendo ser alimentadas e deliberadamente acarinhadas por pais e professores (Gordon, 1998).

Os cursos T.E.T. de Gordon mostram como se faz isto. Por exemplo: um professor pode aprender a usar o "Ouvir Activamente" ou "Escuta Activa" (ver secção seguinte).

\subsubsection{Capacidades que ajudam o aluno a respeitar os direitos dos professores}

Uma forma de responder às mensagens dos jovens, que é de longe mais eficaz do que as frases que simplesmente convidam a falar, é, como referimos, usar o "Ouvir Activamente" ou "Escuta Activa", que aumenta grandemente a eficácia da actividade do professor, ajudando os alunos com problemas que interferem na aprendizagem. Esta ajuda é fornecida de tal forma que capacita o aluno a encontrar o seu próprio caminho. Quando os alunos têm a oportunidade de serem eles próprios a assumir a responsabilidade pela resolução dos seus problemas, o resultado é um aumento da autonomia (Gordon, 1998).

O modelo de gestão da aula de Gordon é idêntico à filosofia do papel dos pais e orientadores, é a real interpretação da regra de ouro: Faz aos outros o que gostarias que te fizessem a ti...

Quando um professor é um "Ouvinte Activo" dos seus alunos, ele envia a mensagem de que os professores são seres humanos que se preocupam com o que os alunos sentem e com o que pensam. Assim, ensinam aos alunos como é que se ouve alguém; os professores moldam um comportamento que os alunos poderão aprender a imitar. Deste modo os alunos poderão aprender a preocupar-se com as necessidades dos outros e serem eles a "ouvir".

Do mesmo modo, aquando do envio, pelos professores, das "I-Messages" - "mensagens na primeira pessoa", para os alunos, estes aprendem a mudar o seu comportamento, não porque receiem o professor, mas porque querem ter consideração 
pelas necessidades do professor. É assim que aprendem a empatia e esta é a raiz da inteligência emocional, maturidade e autodisciplina.

Ouvir Activamente e as "I-Messages" trabalham em equipa. Logo que os professores e alunos abram a comunicação nos dois sentidos e usem esses dois skills, os problemas e conflitos podem ser resolvidos. Sempre que os professores quiserem influenciar os alunos no sentido de pararem um determinado comportamento, eles podem propor aos estudantes uma sessão de resolução de problemas.

A propósito da capacidade de saber ouvir, Wilmot (2005) no seu artigo LISTEN UP - Helping children deal with difficult emotions - começa por referir o episódio ocorrido nos EUA numa escola em S. Diego, Califórnia, quando um jovem, Andy Williams, com 15 anos matou dois colegas e feriu outros 13. A mãe do jovem, quando ouvida, referiu que nunca tinha dado conta de nada de especial no seu filho para além das coisas normais dos adolescentes. Sempre que algo o aborrecia ela tentava que ele esquecesse o assunto e tentava animá-lo. A pergunta fica no ar: terá este jovem (e tantos outros) sido demasiado "poupado"? Ou será que não devemos ajudar a diminuir as emoções dolorosas dos jovens?

É compreensível que os adultos tentem proteger as crianças fazendo-as esquecer as situações que lhes tragam dor ou sofrimento. Mas impedi-las de falar sobre isso também pode trazer consequências negativas. É como se estivéssemos a dizer que não está certo falar sobre essas coisas. E quanto mais tempo esses pensamentos ficarem dentro deles, pior se sentem, trazendo ao de cima respostas inesperadas.

Não é nada fácil ajudar as crianças e jovens a lidar com emoções difíceis como a tristeza, rejeição, medo e frustração. Não há dúvida que temos mais experiência de vida do que as crianças, e é, por isso, que de cada vez que as vemos tristes, com medo ou ansiedade, respondemos mostrando-Ihes aprovação, apoio, distracção ou aconselhamento. Isto porque, de certo modo, também sentimos com elas e queremos mostrar que o problema tem solução. Por outro lado, quando reagimos com ordens, avisos, moralização ou culpabilização é porque receamos que a situação se torne incontrolável no futuro. Por exemplo, se deixarmos o aluno interromper a aula, hoje, assumimos que se torne incontrolável e perturbador nas aulas futuras. Ou temos receio que se uma criança está triste porque um companheiro se meteu com ela, esta se torne demasiado sensível no futuro?

Os efeitos de "Varrer as emoções para debaixo do tapete" tal como diz Wilmot (2005), são reacções comuns e são claramente uma tentativa para ajudar a criança. Mas como recebem e interpretam elas estas mensagens e emoções? Felizmente 
existem maneiras de lidar com situações em que as crianças manifestam as suas emoções, tanto as aceitáveis como o medo e a ansiedade, ou tais como as negativas, como o ódio e a hostilidade.

Saber ouvir correctamente exige consciencialização e compreensão. Também segundo Wilmot (2005) existem quatro aptidões básicas para saber ouvir:

1. Ouvir passivamente: a maioria das crianças sente-se encorajada a continuar a falar; nesta situação o foco é tentar entender qual a mensagem que a criança quer transmitir.

2. Expressões de reconhecimento ("Uh-huh", "claro", "estou a ver") acompanhadas de gestos que comuniquem atenção por parte do ouvinte.

3. Abrir Portas (convite para continuar a falar): o adulto mostra à criança que está atento aos seus sentimentos e que quer ouvi-la sem fazer comentários ou julgamentos "Queres falar sobre isso?", "Estás a pensar em quê?".

4. Ouvir activamente: esta é, porventura, a aptidão mais eficaz. Deve ser como um espelho, isto é, deve reiterar a mensagem que lhe está a ser transmitida. À medida que vai repetindo as palavras da criança, esta, pode corrigir, se estiver a ocorrer algum mal entendido (contra-feedback).

Mesmo que aparentemente os problemas dos alunos pareçam problemas menores aos olhos dos adultos, estes podem vir a ser a causa de grandes questões, sendo, por isso, importante ouvi-los quando eles quiserem dizer algo, independentemente da avaliação superficial da sua "gravidade".

Wilmot (2005) pergunta-se se o jovem assassino Andy Williams não teria tido uma vida diferente se tivesse tido a oportunidade de falar sobre as suas frustrações e dor e se tivesse aprendido maneiras de canalizar esses sentimentos negativos. Ouvir activamente é, sem dúvida, uma ciência e uma arte. Por vezes quem inicia esta aptidão não faz mais do que papaguear exactamente o que a outra pessoa diz, o que, sendo já alguma coisa, pode ser desconfortável e artificial, tanto para o ouvinte, como para quem está a falar.

Do mesmo modo, também há alturas em que não é adequado ouvir as crianças. Quando se está a ensinar algo, na aula, e o comportamento deles é inapropriado e desordeiro, o conselho "sê um bom ouvinte" deve ser ignorado. Em vez disto, devem ser enviadas aos alunos mensagens confrontando-os com a interferência que estão a fazer com os direitos do professor. No entanto a palavra confrontar tem uma 
carga negativa e é normalmente associada a mensagem com conteúdo negativo para o receptor. Estas são as "You-Messages". Em vez destas, o T.E.T. aconselha o uso das "I-Messages" que contêm informação sobre o professor (emissor) em vez de conter mensagens sobre os alunos (receptor). "Estou absolutamente zangada e irritada com a tua atitude" é, pois, uma melhor verbalização do que "a tua atitude é muito má".

\subsubsection{Uma única filosofia para todas as idades e todos os tipos de alunos}

A maioria dos livros acerca de ensinar, fala em diferentes estratégias para cada idade e tipo de aluno. É verdade que é preciso ter em consideração os níveis de ensino de cada aluno para determinar os materiais e experiências educacionais, mas as relações humanas entre professor e alunos são sempre as mesmas. Neste sentido, o critério da verdade, da expressão de sentimentos e da "negociação" é universal para todas as faixas de idade e para todas as situações.

Os professores, no processo de construção e fortalecimento da relação que estabelecem com os alunos, de forma a potenciarem o seu desenvolvimento pessoal e intelectual, deverão procurar desempenhar vários papéis em simultâneo e de forma complementar, dos quais se destacam (Marín \& Pérez, 1985):

1. Animador - o professor será, antes de tudo, animador dos seus alunos e dedicará mais tempo à planificação e avaliação do processo de ensino/aprendizagem. Deverá ajudar os alunos a estabelecer relações satisfatórias com os seus colegas e ensinar-lhes a ser parte integrante e activa da sociedade;

2. Diagnosticador - pede-se ao professor sensibilidade para diagnosticar os factores emocionais que estão presentes no grupo-turma e as consequências do comportamento tanto a nível de trabalho como de formação do grupo;

3. Facilitador do processo de aprendizagem - uma função importante do professor actual é a de criar situações de aprendizagem e fomentar a motivação para aprender. Ensinar a aprender, utilizando as mais diversas estratégias e recursos variados de modo a permitir que o aluno construa activamente o seu conhecimento;

4. Criador de consenso - o professor deve fomentar a tomada de decisões de forma colaborativa e participada por todos;

5. Agente de mudança - A mudança social e cultural que caracterizam os nossos tempos, exige do professor uma mudança permanente no sentido de se adap- 
tar às solicitações da sociedade, em geral, e dos alunos em particular que têm necessidades e exigências decorrentes da sociedade em que vivem.

\section{Características e importância das comunidades de aprendizagem}

As sugestões pragmáticas de sensibilidade afectiva de Thomas Gordon podem influenciar positivamente a forma como se desenha e implementa uma dada comunidade de aprendizagem.

Uma comunidade de aprendizagem define-se em termos de comunicação; existe comunidade se se partilha e se troca informação. De facto, comunicação e comunidade têm uma origem comum. O termo "comunicação" vem do latim "comunis" (comum), ou de "comunicare" (estabelecer uma comunidade). Contudo, apesar da comunicação servir como base da comunidade, os dois conceitos não devem ser confundidos.

$\mathrm{Na}$ Internet, pode ser mais importante o sentimento de comunidade do que o de comunicação. Este sentimento de comunidade é essencial na vida das comunidades de aprendizagem na web, já que estas necessitam de algo mais do que o simples acto de ligação à rede. A chave está na interacção humana através dos computadores. Enquanto que as comunidades físicas estabelecem determinadas relações, as comunidades de aprendizagem na web têm outro tipo de lógica e outro tipo de relações mas, não deixam de ser comunidades, isto é, geram sociabilidade, relações e redes de relações humanas, normas de comportamento e mecanismos de organização.

Segundo Dias, as linhas que devem nortear o desenvolvimento das comunidades de aprendizagem passam, fundamentalmente, por: "simular a diversidade de contextos próprios aos problemas do mundo real, confrontar e partilhar a diversidade de interpretações dentro da comunidade escolar, alargar esta actividade problematizante à conversação com os profissionais no mundo real" (1994, p. 147).

A existência de objectivos comuns é a razão de ser de uma comunidade de aprendizagem. É com vista à concretização de um objectivo comum que a comunidade de aprendizagem existe e se mantêm. Os objectivos comuns não necessitam de ser fixos e rígidos, pelo contrário, devem estar sempre a ser revistos, visando garantir uma actualização de acordo com os interesses e desafios que surgem a partir das 
próprias acções dos membros da comunidade e das acções que esta comunidade sofre do meio onde está inserida.

Todas as comunidades de aprendizagem possuem uma intencionalidade que é compactuada com todos os seus membros. É a partir dessa intenção que são formuladas as acções que serão desencadeadas. De notar que, para todos os efeitos, são mais conhecidas, mais popularizadas, em maior número e mais estudadas, porventura, comunidades de aprendizagem no ensino superior onde, em muitos casos, começaram a existir, primeiro e mais intensamente, as condições logísticas para tal (Morais et al., 1999).

O estabelecimento de uma comunidade aprendente confere aos seus participantes aptidões que Ihe darão qualidades profissionais importantes. Laferrière (1997) estabelece seis fases para o desenvolvimento da autonomia do participante e das comunidades aprendentes na Web, em geral:

Fase I - Desenvolver uma consciência do fenómeno da rede de Internet; consiste no desenvolvimento de uma consciência que emerge das expectativas sociais

Fase II - Dominar a Internet e os seus recursos; consiste na capacidade de ter acesso, analisar e dar sentido à informação disponível assim como ser capaz de falar, criar e comunicar através das TIC.

Fase III - Ver novas possibilidades para o ensino e aprendizagem; com a ligação dos computadores em rede, apresenta-se aos professores uma nova variedade de possibilidades que, com criatividade e imaginação pedagógica, farão uso delas.

Fase IV - Estabelecer novas rotinas de gestão da aula; estabelecer tempo para a aprendizagem e uso das tecnologias na sala de aula (ex. X minutos para ver o e-mail, x horas para aprender uma determinada aplicação, etc.).

Fase $V$ - Coordenar a aprendizagem baseada na elaboração de projectos; todos os envolvidos no processo da aprendizagem devem envolver-se em projectos que estão directamente ligados ao curriculum. Podem usar as TIC em variadas estratégias de ensino e aprendizagem, principalmente naquelas em que há um enorme envolvimento.

Fase VI - Comunidades construídas no conhecimento; o desafio é que todo o processo de comunicação (entre alunos, escolas, alunos de licenciaturas ligados a diferentes escolas e professores, supervisores universitários, etc.) crie um sistema 
dominado pela construção do conhecimento e partilha de experiência, criando assim um ambiente imbuído de transformação permanente.

As comunidades de aprendizagem apresentam em comum um aspecto: a colaboração como razão para a constituição de uma determinada comunidade, como exigência para a sua manutenção e como consequência do seu funcionamento.

Numa comunidade de aprendizagem, a colaboração apresenta-se como uma acção voltada para uma mesma intencionalidade, para um mesmo objectivo comum (Husserl, 1937). Os aspectos colaborativos são caracterizados pelo mútuo envolvimento nas actividades da comunidade, na partilha do conhecimento entre os seus membros e na participação conjunta na construção das aprendizagens. Os membros da comunidade desenvolvem redes de partilha e construção flexível e colaborativa das aprendizagens que suportam a exploração da multidimensionalidade das representações de conhecimento. A actividade da comunidade de aprendizagem é o meio de amplificação das capacidades cognitivas individuais para o grupo, orientadas para o desenvolvimento colaborativo do pensamento reflexivo e dos processos criativos.

Quanto à natureza da colaboração na rede, "(...) as novas comunidades virtuais são agrupamentos sociais que emergem da Internet, quando são estabelecidas redes de interacções mediadas por computador entre os sujeitos, orientadas pela partilha de interesses e com a duração suficiente para criarem vínculos no ciberespaço." (Dias, citado por Chagas, 2002, p. 73).

Nesta ou noutra "definição" de comunidades virtuais pode pontuar uma atitude de melhor "lubrificação" nas relações entre professores, alunos e encarregados de educação. Segundo Gordon (1998) opõe-se aos métodos I (autoritarista) e II (lascivo e sem balizas), o virtuoso método III, baseado na negociação e por ele apelidado de método "sem vencidos". No estabelecimento de comunidades que partilham e que, na sua diversidade, se encontram numa certa horizontalidade, que melhor lema poderá nortear os caminhos: "sem vencidos"... só com vencedores!

\section{Considerações finais}

Como temos vindo a referir, a relação que se estabelece entre os alunos e o professor é que determina a qualidade do ensino e da aprendizagem. O desafio para os professores é melhorar a qualidade desse relacionamento, de modo a que os alunos exteriorizem o que de melhor há dentro deles quando estão a aprender. 
A colaboratividade não é só benéfica, no sentido social do termo, relacionado com aptidões transferíveis de âmbito não estritamente de aprendizagem. Além do reforço de competências várias, fulcrais na sociedade do conhecimento e da informação, a colaboratividade conduz a mais significância e consistência, mesmo no plano da aprendizagem cognitiva. "As rotinas escolares recíprocas e lineares dão origem a muito depressivas participações dos estudantes, tangendo a apatia. Pelo contrário, apresentam melhores resultados e são muito mais activos os alunos que participam em actividades colectivas" (Resnick, 1989, p. 399). Notar que Freire (1972) centra a prática educativa não como uma recepção de conhecimentos ou mesmo aptidões ou competências, mas como uma forma do aprendente se apropriar da sua realidade para a transformar. E, cada vez mais na actual sociedade, nenhuma realidade se transforma verdadeiramente com um contributo meramente individual e sem a colaboração recíproca de vários elementos.

Julgamos que esta breve abordagem das ideias de Thomas Gordon terá demonstrado a importância e o proveito para a escola de trilhar os caminhos apontados por este autor. As ideias de Gordon sustentam fortemente as comunidades escolares de aprendizagem, nas quais os indivíduos são muito mais do que coleccionadores passivos de informação, tornando-se parceiros do processo de aprendizagem. As TIC constituem-se também como elementos potenciadores deste processo de construção e colaboração que ocorre nas comunidades escolares com suporte digital. Professores, alunos e encarregados de educação poderão com eficácias redobradas trilhar profícuas comunidades educativas em novos ambientes tecnológicos usando algumas das pistas de Gordon explanadas nesta reflexão. Fóruns de discussão mediados digitalmente, permutas intensas de emails, chats e outras interacções digitais podem ganhar mais vigor se balizadas com critérios de "negociação", ao estilo gordoniano.

\section{Bibliografia}

Almenara, J. (1996). Nuevas Tecnologías, Comunicación y Educación. EDUTEC, Revista Electrónica de tecnología Educativa, 1.

Castells, M. (2000). The Rise of the Network Society (2nd Ed). Malden: Blackwell Pub.

Chagas, I. (2002). Trabalho em colaboração: condição necessária para a sustentabilidade das redes de aprendizagem. In Conselho Nacional de Educação Redes de Aprendizagem, Redes de Conhecimento (pp. 71-81). Lisboa: Ministério da Educação.

Dias, P. (1994). A Abordagem da Comunicação Multidimensional na Concepção e Desenvolvimento de Interfaces Hipermedia. In D. A. Rodrigues e J. P. Ponte 
(orgs.), Actas do II Congresso Ibero-americano de Informática na Educação. Lisboa: DEPGEF.

Dias, P. (2000). Hipertexto, hipermédia e media do conhecimento: representação distribuída e aprendizagens flexíveis e colaborativas na Web. Revista Portuguesa de Educação, 13.

Dias, P. (2004).Comunidades de aprendizagem e formação on-line. Nov@Formação, Ano 3, N. $-3,14-17$.

Freire, P. (1972). Pedagogia do Oprimido. Porto: Afrontamento.

Gordon, T., \& Burch, N. (2002). P.E.E. Programa do Ensino Eficaz. Lisboa: Escola Superior de Educação João de Deus.

Gordon, T. (2005). The Power of the Language of Acceptance. Gordon Training International, 1. Consultado Janeiro 07, 2008, em http://www.gordontraining.com/languageofaccept.html

Gordon, T. (1998). Eficácia na Educação dos filhos. Lisboa: Encontro Editora.

Husserl, E. (1937). La crise des sciences européennes et la phénoménologie transcendantale, Trad. Gérard Guest. Paris: Gallimard.

Laferrière, T. (1997). A six-phase tentative general model of professional development. Proceedings of The 14th International Conference on Technologies and Education, 556-558. Consultado Janeiro 07, 2008, em http://www.tact.fse.ulaval.ca/ model/ang/model.html

Marín, I., \& Pérez, S. (1985). Pedagogía Social e Sociología de la Educación. Madrid: UNED.

Morais, C., Miranda, L., Dias, P., \& Almeida, C. (1999). Tecnologias de informação na construção de ambientes de aprendizagem. In P. Dias \& C. V. Freitas (Eds), Actas do Challenges 1999, I Conferência Internacional de Tecnologias de Informação e Comunicação na Educação (pp. 221-231). Braga: Centro de Competência Nónio Século XXI da Universidade do Minho.

Paiva, J. (2007). As Tecnologias de Informação e Comunicação na Educação: Diagnósticos, reflexões e uma experiência com o e-mail numa escola de 3o ciclo, Tese de Doutoramento em Ciências da Educação. Coimbra: Faculdade de Psicologia e Ciências da Educação da Universidade de Coimbra.

Pereira, D. (2006). Nova ciência para a nova educação na nova sociedade. Porto: Editora UP.

Resnick, L. (1989). Knowing, Learning and Instruction. New Jersey: Lawrence Erlbaum.

Rheingold, H. (1997). Internet and education: the need for the individual to think critically. Interview: MediaMente, Agosto 15, 1997, 4. Consultado Janeiro 07, 2008, em http://www.mediamente.rai.it/mmold/english/bibliote/intervis/r/rheingol.htm

Terceiro, J. (1997). Socied@de Digit@l, do homo sapiens ao homo digitalis. Lisboa: Relógio d'Água.

Wilmot, J. (2005). Listen Up - Helping children deal with difficult emotions. Gordon Training International, 1-5. Consultado Janeiro 07, 2008, em http://www.gordontraining.com/listenup.html 


\section{Résumé}

Un des facteurs de changement en éducation implique que celle-ci soit davantage un processus de communication authentique, ouvert et clair, pas seulement entre les enseignants et les élèves, mais aussi parmi tous les intervenants au processus éducatif, incluant, en particulier, les parents. On n'apprend qu'à l'intérieur d'un contexte communicationnel participatif, interactif et existentiel. Les technologies de la communication peuvent être un précieux auxiliaire / instrument, en ce contexte. Dans la communication virtuelle, des communautés d'apprentissage s'établissent, soutenues par les piliers provenant des idées de Thomas Gordon. Cet auteur a mis de façon simple et opérationnelle les règles de l'intelligence émotionnelle et celles de la psychologie humaniste au service de l'éducation. Ses suggestions ont été transposées à la communauté éducative, ouvrant de très intéressantes voies à la "négociation" affective entre les élèves, les enseignants et les parents. Cette approche peut favoriser aux contextes éducationnels la qualité et la quantité des communautés digitales.

\footnotetext{
Abstract

One of the changes in education involves its transformation through a process of real communication, open and truthful. Not only between teachers and students but also between them and all the intervenients in the education process, particularly parents. You can only learn deeply, within a participating, interactive and existential communicational context. The ICT can be, in this context, a valuable lever. In virtual communication, learning communities are established, sustained by some of Thomas Gordon's ideas. This author puts on a very simple and operational way, precepts of emotional intelligence and of humanist psychology concerning education. His suggestions were then used in schools, which supplied very interesting clues for the affection "negotiation" between students, teachers and parents. Such a context may promote the quality and the amount of digital communities in educational environment.
} 